\title{
Toprak Makrofaunasının Saf ve Karışık Meşcerelerdeki Komünite Yapıları
}

\author{
Meriç ÇAKIR ${ }^{1 *}$, Ender MAKINECí ${ }^{2}$ \\ ${ }^{1}$ Çankırı Karatekin Üniversitesi, Orman Fakültesi, Toprak İlmi ve Ekoloji Anabilim Dalı, 18200, Çankırı \\ 2 İstanbul Üniversitesi-Cerrahpaşa, Orman Fakültesi, Toprak İlmi ve Ekoloji Anabilim Dalı, 34473, \\ Sarıyer/İstanbul
}

\section{Öz}

Toprak makrofaunası, farklı trofik gruplar içeren ve boyutları $2 \mathrm{~mm}$ 'den büyük olan eklembacaklılar ile yumuşak vücutlu omurgasızları içermektedir. Makrofauna, ayrışma, besin döngüsü, toprak strüktürü ve hastalık yapan canlıların popülasyon yoğunluğunu dengede tutmak gibi önemli ekosistem fonksiyonlarını etkiler. Ayrıca bitkilerin çeşitliliğini, bolluğunu, süksesyonunu ve üretimini etkileyen biyojeokimyasal döngülerde çok önemli rolleri vardır. Saf meșe (Quercus petraea L.) ve kayın (Fagus orientalis L.) meșcereleri ile meșe-kayın karıșık meşceresinde yürütülen çalışmada makrofaunanın miktar, çeşitlilik ve komünite yapılarının araştırılması amaçlanmıştır. İstanbul Belgrad Ormanı içerisinde yer alan Atatürk Arboretumu'unda yürütülen çalıșmada makrofaunayı örneklemek için çukur tuzaklar kullanılmıştır. Örnekleme aylık olarak bir yıl boyunca yapılmıștır. Meșe-kayın karışık meșceresinde (606 bry. $\mathrm{m}^{-2}$ ) makrofauna miktarı saf meşe (478 bry. $\mathrm{m}^{-2}$ ) ve saf kayın meşceresine (470 bry. $\mathrm{m}^{-2}$ ) kıyasla istatistiksel olarak fazla bulunmuştur. Shannon çeşitlilik indeksine göre makrofauna çeșitliliği meșe $\left(H^{\prime}=1,24\right)$, kayın $\left(H^{\prime}=1,29\right)$ ve meșe-kayın $\left(H^{\prime}=1,28\right)$ meșcereleri arasında önemli bir fark çıkmamıştır. Genel olarak saf ve karışık meșcerelerdeki en baskın trofik grubu yırtıcılar oluşturmaktadır.

Anahtar Kelimeler: Makroeklembacaklı, Komünite, Trofik grup, Toprak faunası, Meşe, Kayın.

\section{Community Structure of Soil Macrofauna Under Pure and Mixed Forest Stands}

\begin{abstract}
Soil macrofauna includes arthropods and soft-bodied invertebrates with different trophic groups and sizes larger than $2 \mathrm{~mm}$. Macrofauna affects important ecosystem functions such as decomposition, nutrient cycling, soil structure, and suppression of population density of pathogens. Besides, they play an important role in biogeochemical cycles that affect plant diversity, abundance, succession, and production. The study conducted on pure oak (Quercus petraea L.) and beech (Fagus orientalis L.) stands and oak-beech mixed stands, it was aimed to investigate the density, diversity, and community structures of macrofauna. Pitfall traps were used to collect the macrofauna in the research area in the Atatürk Arboretum located in the Belgrad Forest of Istanbul. Sampling was done monthly for one year. Macrofauna density was found statistically higher in the oak-beech mixed stand (606 bry. $\mathrm{m}^{-2}$ ) compared to pure oak (478 bry. $\mathrm{m}^{-2}$ ) and pure beech stand (470 bry. $\mathrm{m}^{-2}$ ). According to the Shannon diversity index, there was no significant difference in macrofauna diversity between oak $\left(H^{\prime}=\right.$ 1.24), beech $\left(H^{\prime}=1.29\right)$ and oak-beech $\left(H^{\prime}=1.28\right)$ stands. In general, predators constitute the most dominant trophic group in pure and mixed stands.
\end{abstract}

Keywords: Macroarthropod, Community, Trophic group, Soil fauna, Oak, Beech. 


\section{Giriş}

Makrofaunanın, ayrımında vücut boyu dikkate alınmaktadır ve $2 \mathrm{~mm}$ boyundan daha büyük canlılar bu sınıfa girmektedir (Swift ve ark., 1979). Makrofauna, Insecta, Isopoda, Myriapoda, Arachnida gibi eklembacaklılar ile birlikte Gastropoda ve Oligochaeta gibi yumuşak vücutlu omurgasızları kapsamaktadır. Makrofauna içerisinde Diplopoda, Isopoda ve Gastropoda ölüörtü ile beslenen önemli ayrıştırıcı grubu oluştururken, Chilopoda, Arachnida, Opiliones ve bazı böcekler (Carabidae ve Staphylinidae gibi) diğer toprak faunası ile beslenen avcı (predatör) grubun üyeleridirler.

Makrofauna, ayrışma, besin döngüsü, toprak strüktürü ile hastalık yapan canlıların popülasyon yoğunluğunu dengede tutmak gibi önemli ekosistem fonksiyonlarını etkilemektedir. Ayrıca makrofauna toprak ekosisteminin ve besin döngüsünün önemli bir parçasıdır. Makrofauna daha küçük faunaya (mezofauna) kıyasla toprak yapısını doğrudan değiştirebilir (Lee ve Foster, 1991). "Ekosistem mühendisleri”" olarak adlandırılan karıncalar ve toprak solucanları bulundukları çevrenin fiziksel, kimyasal ve biyolojik özelliklerini değiştirerek ekosistem fonksiyonlarını etkilemektedirler (Jones ve ark., 1994). Toprak makrofaunası toprak içerisindeki faaliyetleri ile alt katmanlardaki toprağı üst katmanlara çıkartırken ölüörtüde bulunan organik maddenin de toprağın alt katmanlarına ulaşmasına katkı sağlarlar (Coleman ve ark., 2004). Yukarıda belirtilen faaliyetleri ile makrofaunanın bitki büyümesi ve birincil üretime önemli etkileri olmaktadır (Barros ve ark., 2001; Frouz ve ark., 2006). Toprak makrofaunasının bitkilerin çeşitliliğini, bolluğunu, süksesyonunu ve üretimini etkileyen biyojeokimyasal döngülerde çok önemli rolleri vardır ve bu yolla ekosistem süreçlerini de etkilemektedirler (Petersen ve Luxton, 1982; Hättenschwiler ve Gasser, 2005; Bardgett ve van der Putten, 2014). Aynı zamanda bitki çeşitliliği de toprak faunasını doğrudan (ölü örtü kalitesi) ve dolaylı (pH ve toprak nemi) olarak etkilemektedir (Korboulewsky ve ark., 2016).

Ağaç türlerinin toprak makrofaunası üzerine olan etkileri ile ilgili birçok çalışma (Binkley ve Menyailo, 2005; Vehviläinen ve ark., 2008; Korboulewsky ve ark., 2016) olmasına rağmen saf ve karışık meşcerelerin toprak faunasının miktar ve çeşitliliğine olan etkisi ile ilgili çok az çalışma mevcuttur (Scheu, 2005; Wardle ve ark., 2006). Karışık meşcereler, saf meşcerelere kıyasla biyotik zararlılara (Jactel ve Brockerhoff, 2007) ve kuraklığa karşı (Merlin ve ark., 2015) daha dirençli olmaları ve ayrıca yüksek verim güçleri nedeni ile (Pretzsch ve ark., 2010; Vallet ve Pérot, 2011) bütün dünyada tercih edilmektedir. Karışık meşcereler ayrıca bitkiler ve hayvanlar için daha fazla tür çeşitliliğine sahiptir. Karışı meşcerelerin orman biyoçeşitliliği üzerindeki etkileri ile ilgili yapılan çalışmaların büyük bir kısmı bitkiler üzerine odaklanmaktadır (Scherer-Lorenzen ve Schulze, 2005; Barbier ve ark., 2008; Cavard ve ark., 2011). Bu çalışmalarında çok az kısmı mezofaunanın miktar ve çeşitliliği (Scheu ve ark., 2003; Salamon ve ark., 2008; Korboulewsky ve ark., 2016) ile ilgiliyken makrofauna ile ilgili çalışmalar yetersizdir.

Bitki çeşitliliğinin toprak faunasını, besin çeşitliliğini ve kalitesini arttırarak olumlu etkilediği bilinmektedir (Wardle ve ark., 2004). Ayrıca farklı nişler oluşturarak miktar ve çeşitliliğinide etkilediği belirtilmiştir (Cakir ve Makineci, 2013). Bu bilgiler ışı̆̆ında bu çalışma saf meşe (Quercus petraea L.) ve saf kayın (Fagus orientalis L.) meşceresi ile meşe-kayın karışık meşceresindeki toprak makrofaunasının miktar, çeşitlilik ve komünite yapılarını belirlemeyi amaçlamaktadır.

\section{Materyal ve Metot}

\section{1. Çalışma Alanı}

Araştırmanın yapıldığı örnek alanlar İstanbul Belgrad Ormanı içerisinde yer alan Atatürk Arboretumu’nda bulunan doğal meşe, kayın ve meşe-kayın karışık meşcerelerinden alınmıştır. Atatürk Arboretumu, İstanbulSarıyer ilçesi sınırları içerisinde Belgrad Ormanı'nın güney doğusunda 296 ha'lık bir alanı kapsamaktadır.

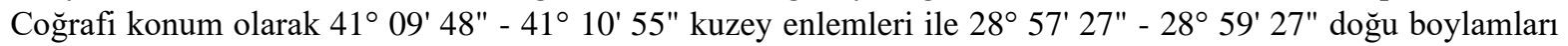
arasında bulunmaktadır. Denizden yüksekliği 65-166 m arasında değişmektedir. Arazinin genel bakısı güneydoğu ve güney-batı yönünde olmasına rağmen değişik yönlere dönük çok fazla küçük yamaçlar bulunmaktadır (Karaöz, 1991). 


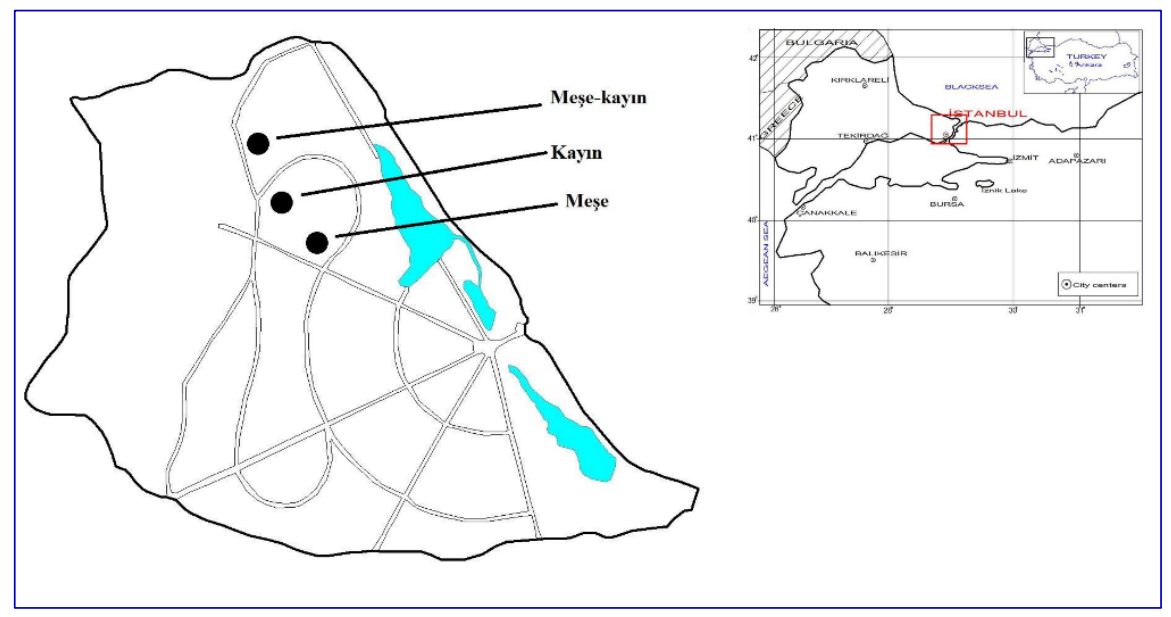

Şekil 1. Atatürk Arboretumu (İstanbul) içerisinde bulunan saf ve karışık örnek alanlar.

Uzun dönem meteorolojik (1975-2008) verilere göre yıllık ortalama yağış $1111 \mathrm{~mm}$, ortalama sıcaklık $13{ }^{\circ} \mathrm{C}$ 'dir (Akburak ve Makineci, 2016). Çalışma sırasındaki (Haziran 2009 - Haziran 2010) yıllık yağış 1070 mm, yıllık ortalama sıcaklık 14,9 ${ }^{\circ} \mathrm{C}$ 'dir (MGM, 2013). Atatürk Arboretumu'nda topraklar genellikle killi olup balçıklı kil ve kil türünde topraklar yaygındır (Çepel ve Günay, 1984). FAO Dünya Referans Temeline göre bulunan referans toprak grupları Stagnosol, Alisol, Acrisol ve Cambisol dür (WRB, 2006; Özturna, 2013). Çalışma alanlarında ortalama çap ve boy değerleri sırası ile meşe alanında $10,28 \mathrm{~cm}$ ve $16,8 \mathrm{~m}$, kayın alanında 18,15 ve $22,3 \mathrm{~m}$ ve meşe-kayın alanında meşe: $14,20 \mathrm{~cm}$, kayın: $20,82 \mathrm{~cm}$ ve 22,5 m olarak belirlenmiştir. Bütün alanlar doğu bakıda ve 55-60 yaşlarındadır (Çakır ve Makineci, 2020).

\subsection{Makrofaunanın Örneklenmesi}

Makrofauna için en çok kullanılan örnekleme yöntemi çukur tuzaklardır (Leather, 2005). Her bir örnek alanda 9 noktaya, 9 cm yüksekliğinde ve $7 \mathrm{~cm}$ çapında plastik toplama kabı, üst kısmı toprak seviyesinde olacak şekilde gömülmüştür (Santos ve ark., 2007). Toplama kabının içerisine düşen canlının tanımlanmasını zorlaştırmayacak şekilde öldürmek için \% 70 etil alkol ve \% 2 gliserin karışımı konulmuştur (Santos ve ark., 2007). Tuzakların içerisine yabancı maddelerin girmesini engellemek için toprak yüzeyinden 3-4 cm yukarıya, canlıların girişine izin verecek yükseklikte çatılar konulmuştur (Leather, 2005). Makrofaunanın örneklenmesi Haziran 2009 ile Mayıs 2010 tarihleri arasında aylık olarak yapılmıştır. Örnek alanlarda 24 saat bekleyen toplama kapları içerisine düşen canlılar, toplama kabı içerisindeki çözeltiden süzülerek plastik ağzı kilitli torbalara alınmış ve teşhisleri yapılmak üzere laboratuvara götürülmüştür. Makrofaunanın tanımlanması Dindal (1990)'a göre yapılmıştır.

\section{3. İstatistiksel Yöntemler}

Saf ve karışık meşcerelerdeki makrofaunaya ait her bir örnekleme zamanı için elde edilen miktar ve çeşitlilik değerleri varyans analizi (ANOVA) ile \% 95 güven düzeyinde $(\alpha=0,05)$ karşılaştırılmıştır. ANOVA sonuçları, istatistiki olarak farklılık gösteren değişkelerin ortalamaları Tukey post hoc testi ile ayrılmıştır. Ayrıca meşcereler arası zamansal olarak farklılığın belirlenebilmesi için tekrarlı ölçümlerde ANOVA testi yapılmıştır. İstatistiki analizlerde SPSS programından yararlanılmıştır (SPSS, 2011). Makrofaunaya ait komünite parametrelerinin belirlenmesinde miktar (bry. $\mathrm{m}^{-2}$ ) ve Shannon çeşitlilik indisi $\left(H^{\prime}\right)$ kullanılmıştır (Shannon ve Weaver, 1949).

\section{Bulgular}

\subsection{Makrofaunanın Yoğunluğu}

Çalışma süresince saf ve karışık meşcerelerde yaşayan toprak makrofaunası, meşe meşceresinde 19, kayın meşceresinde 20, meşe-kayın karışık meşceresinde 23 takson ile tanımlanmış ve toplam 1452 birey toplanmıştır. Ocak ve şubat aylarında yoğun kar nedeni ile çukur tuzaklarda makrofaunaya rastlanılmamıştır. Meşe-kayın karışık meşceresinde, saf meşcerelere kıyasla daha fazla makrofauna olduğu belirlenmiştir $(P<0,05)$. Toplam 
makrofauna miktarının yıl içerisindeki değişiminde en büyük istatistiksel fark temmuz ayında meşe-kayın karışık meşceresinde görülmektedir. Ağustos ve Eylül aylarında da meşcereler arasında istatistiksel farklılık görülürken diğer aylarda anlamlı bir fark görülmemektedir (Şekil 2).

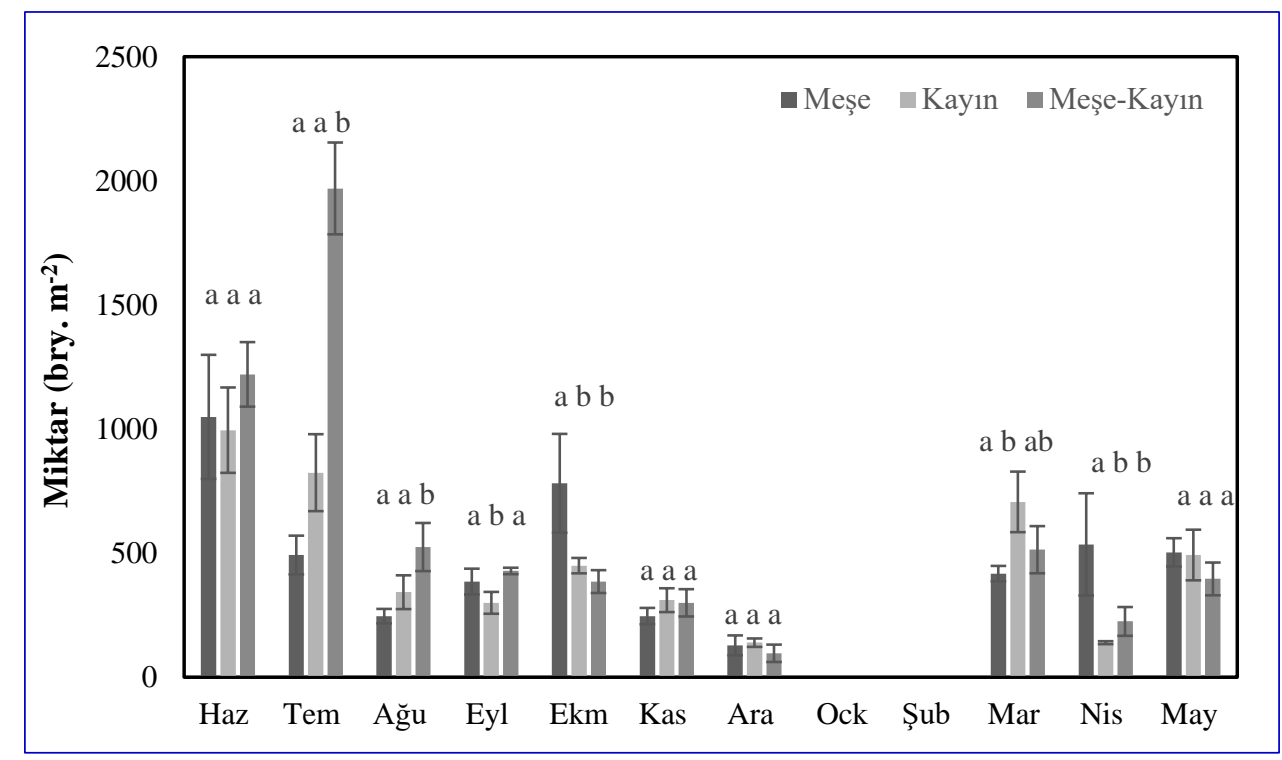

Şekil 2. Makrofauna miktarının (ortıstd.hata) saf ve karışık meşcerelerdeki zamansal değişimi.

Meşe, kayın ve meşe-kayın meşcerelerinde yıllık ortalama makrofauna miktarı sırası ile 478 bry. $\mathrm{m}^{-2}, 470$ bry. $\mathrm{m}^{-2}$ ve 606 bry. $\mathrm{m}^{-2}$ olarak bulunmuştur. Meşcereler arasında makrofauna miktarı, meşe-kayın meşceresinde saf meşcerelere kıyasla önemli derecede farklı $(P<0,05)$ bulunmuştur. Ayrıca makrofauna miktarı hem meşcereler arasında hem de zamansal olarak da farklılık göstermektedir $(P<0,05)$ (Tablo 1).

Tablo 1. Saf ve karışık meşcerelerdeki makrofauna miktarının tekrarlı ölçümlerde ANOVA analiz sonuçları.

\begin{tabular}{lll}
\hline Miktar $\left(\mathbf{b r y ~} \mathbf{~ m}^{-\mathbf{2}}\right)$ & $\mathbf{F}$ & $\boldsymbol{P}$ \\
\hline Meşcere & 7,676 & 0,005 \\
Zaman & 15,012 & 0,000 \\
Meşcere x Zaman & 3,610 & 0,013 \\
\hline
\end{tabular}

Y1l içerisinde en fazla görülen bazı makrofauna taksonları Şekil 3'de gösterilmiştir. Genel olarak Makrofauna miktarı kış aylarında azalma göstermektedir. Carabidae taksonu yıl içerisinde üç meşcerede de sayıca fazla bulunan toprak faunasıdır. En aktif oldukları zaman haziran ekim ayları arasıdır. Pselaphidae taksonu çalışma süresinde sadece kayın ve meşe-kayın meşcerelerinde bulunmuş ve haziran, ağustos ayları arasında aktif oldukları belirlenmiştir. Staphylinidae taksonunun en aktif olduğu zaman eylül, ekim ayları arasındadır. Diptera taksonu ise yaz ayları dişında toprakta ikamet eden ve ağustos ayından sonra topraktaki miktarları kasım ayına kadar artış gösteren toprak faunası üyelerindendir. Julida (Diplopoda) taksonu birim alandaki $\left(\mathrm{m}^{2}\right) \mathrm{miktarları}$ 50'yi aşmayan ve göreceli olarak yaz aylarında daha aktif olan canlılardır. Avcı taksonlar olan Lithobiomorpha, Araneae ve Opiliones taksonlarının miktarı ilkbaharda (mart) artmakta ve sonbaharda (kasım) azalmaktadır. Orthogastropoda taksonu ise eylül, kasım ayları arasında en yüksek yoğunluğuna ulaşmakta ve yaz aylarında aktiviteleri azalmaktadır (Şekil 3). 


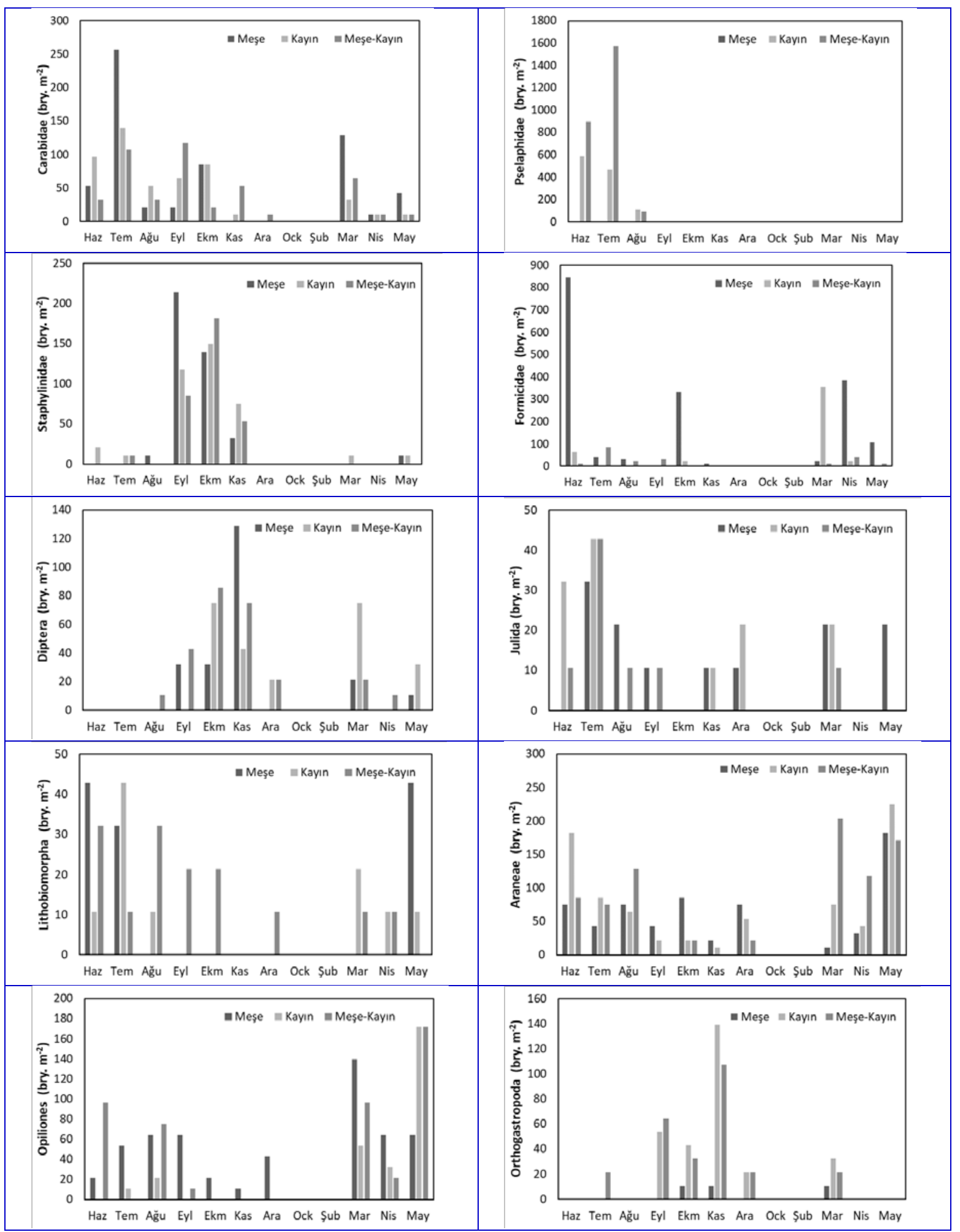

Şekil 3. Bazı makrofauna taksonlarının saf ve karışık meşcerelerdeki miktarlarının zamansal değişimi.

\subsection{Makrofaunanın Komünite Yapısı}

Insecta, meşe (\% 65), kayın (\%63) ve meşe-kayın (\%66) meşcerelerinde toplam makrofauna komünitesinin en büyük kısmını oluşturmaktadır. Diğer baskın taksonları Araneae (sırası ile \%13; \%6; \%8) ve Opiliones (sırası ile \%11; \%6; \%8) oluşturmaktadır. Diğer (Diplopoda, Chilopoda, Isopoda, Microcoryphia, Oligochaeta ve Gastropoda) taksonların toplamı ise toplam faunanın küçük bir kısmını (sırası ile \%10; \%14; \%12) oluşturmaktadır (Tablo 2). 
Tablo 2. Toprak makrofaunasının saf ve karışık meşcerelerdeki miktar (bry.m²) ve oranları (\%) (Çakır ve Makineci, 2020).

\begin{tabular}{|c|c|c|c|c|c|c|c|c|}
\hline \multirow{2}{*}{ Takım } & \multirow{2}{*}{ Alttakım/Familya } & \multirow{2}{*}{ Trofik grup } & \multicolumn{2}{|c|}{ Meșe } & \multicolumn{2}{|c|}{ Kayın } & \multicolumn{2}{|c|}{ Meșe-Kayın } \\
\hline & & & A & $\%$ & A & $\%$ & A & $\%$ \\
\hline \multirow[t]{9}{*}{ Insecta } & Carabidae & Yirtici & 62 & 13,0 & 50 & 10,7 & 46 & 7,6 \\
\hline & Carabid. Larva & Hepçil & 4 & 0,9 & 4 & 0,9 & 3 & 0,5 \\
\hline & Staphylinidae & Yirtic1 & 41 & 8,5 & 40 & 8,4 & 33 & 5,5 \\
\hline & Cerambycidae & Otçul & - & - & - & - & 1 & 0,2 \\
\hline & Formicidae & Hepçil & 178 & 37,1 & 46 & 9,8 & 21 & 3,5 \\
\hline & Caelifera & Otçul & - & - & 1 & 0,2 & 2 & 0,4 \\
\hline & Sphecidae & Yirtici & 1 & 0,2 & - & - & - & - \\
\hline & Vespidae & Yirtici & - & - & - & - & 2 & 0,4 \\
\hline & Diptera & Otçul & 22 & 4,7 & 25 & 5,2 & 27 & 4,4 \\
\hline \multirow{2}{*}{ Diplopoda } & Callipodida & Çürükçül & 2 & 0,4 & - & - & - & - \\
\hline & Polidesmida & Çürükçül & 1 & 0,2 & 1 & 0,2 & 6 & 1,1 \\
\hline \multirow[t]{2}{*}{ Chilopoda } & Lithobiomorpha & Yirtic1 & 12 & 2,5 & 11 & 2,3 & 15 & 2,5 \\
\hline & Scolopendromorpha & Yirtic1 & - & - & - & - & 1 & 0,2 \\
\hline Isopoda & Oniscidae & Çürükçül & 3 & 0,7 & 3 & 0,7 & 7 & 1,2 \\
\hline Microcoryphia & Machilidae & Çürükçül & - & - & 2 & 0,5 & 7 & 1,2 \\
\hline Araneae & Araneae & Yirtic1 & 64 & 13,4 & 78 & 16,6 & 82 & 13,6 \\
\hline Opiliones & Opiliones & Yirtic1 & 55 & 11,4 & 29 & 6,2 & 47 & 7,8 \\
\hline Oligochaeta & Lumbricina & Çürükçül & 11 & 2,2 & 3 & 0,7 & 1 & 0,2 \\
\hline Gastropoda & Orthogastropoda & Otçul & 3 & 0,7 & 29 & 6,2 & 27 & 4,4 \\
\hline
\end{tabular}

(A) birim alandaki $\left(\mathrm{m}^{2}\right)$ toplam birey sayısı, $(\%)$ toplam sayıya göre her taksonun oransal değeri.

Makrofaunayı oluşturan taksonların beslenme alışkanlıkları (trofik grup) içerisinde yırtıcılar, çürükçüller, otçullar ve hepçiller bulunmaktadır. Trofik grupların yıl içerisindeki değişimi incelendiğinde saf meşe meşceresi içerisindeki trofik grupların oranı, saf kayın ve meşe-kayın karışık meşceresine kıyasla bazı farklılıklar göstermektedir (Şekil 4). Toprak makrofaunası içerisinde oransal olarak en baskın trofik grubu avcılar oluşturmaktadır. Farklı trofik seviyelerdeki grupların komünite içerisindeki oranları yıl içerisinde değişiklik gösterebilmektedir. Yaz aylarında yırtıcılar baskınken eylül ayından sonra Orthogastropoda ve Gryllidae taksonlarındaki artış otçul oranını arttırmıştır. Meşe meşceresinde haziran ve nisan ayında Formicidae taksonundaki artış hepçil oranında artışa neden olmuştur. Benzer olarak, kayın meşceresinde de mart ayında Formicidae taksonundaki artış hepçil oranında artışa neden olmuştur (Şekil 4). 


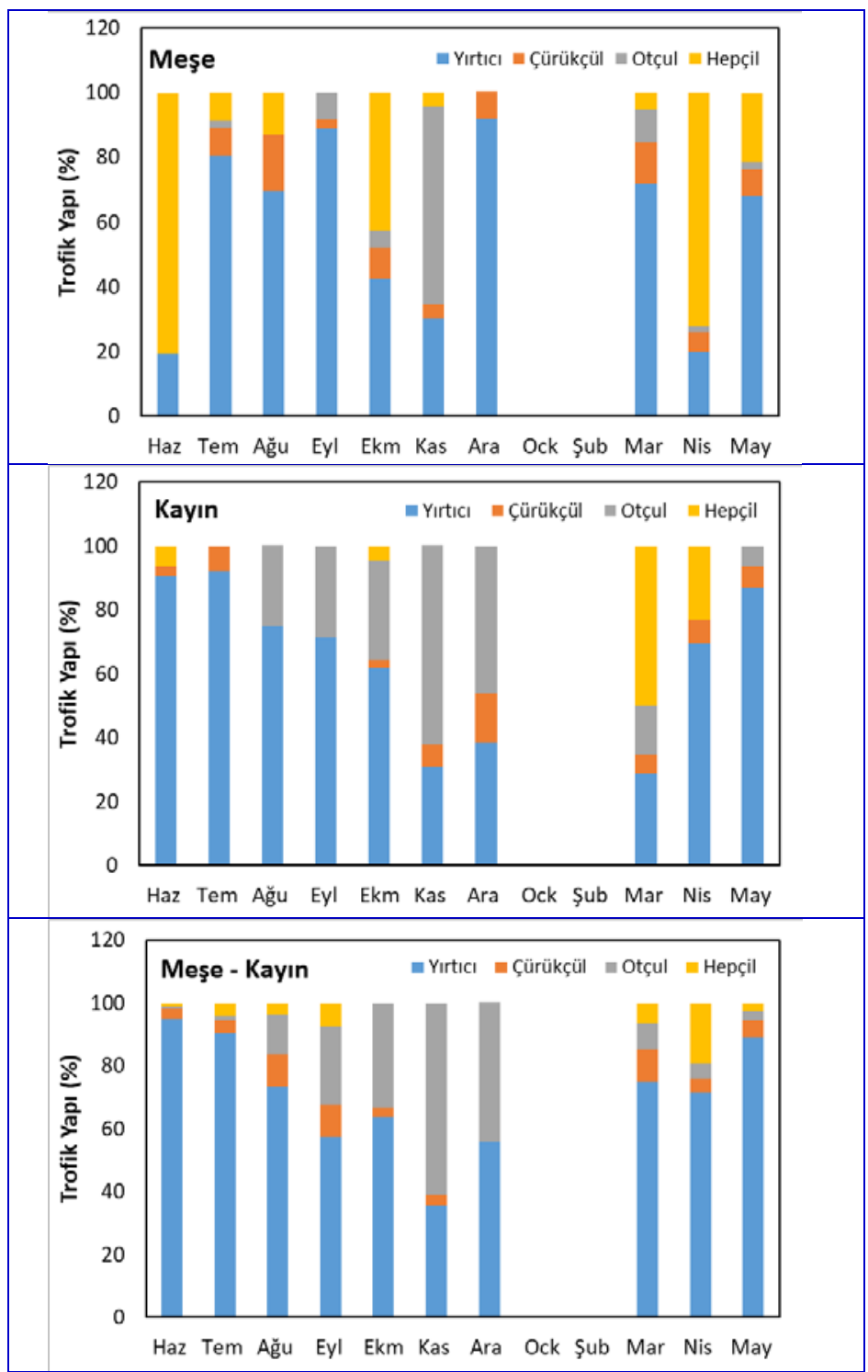

Şekil 4. Saf ve karışık meşcerelerdeki makrofaunanın trofik yapısının yıl içerisindeki değişimi.

Saf ve karışık meşcerelerin trofik gruplarının yıllık ortalama oranları kendi içerisinde karşılaştırıldığında en büyük grubu yırtıcılar oluşturmaktadır ve istatistik olarak diğer gruplardan farklılık göstermektedir $(P<0,05)$. Farklı trofik seviyeler meşcere bazında karşılaştıııldığında istatistiksel fark bulunamamış̦ır $(P>0,05)$.

Tablo 3. Farklı trofik seviyelerdeki toprak makrofaunasının saf ve karışık meşcerelerdeki yıllık ortalama oranı.

\begin{tabular}{lllllll}
\hline & Yırtıcı & Çürükçül & Otçul & Hepçil & F & P \\
\hline Meşe (\%) & $58,20 \pm 8,84^{\mathrm{a}}$ & $7,90 \pm 1,56^{\mathrm{b}}$ & $9,00 \pm 5,88^{\mathrm{b}}$ & $24,70 \pm 9,51^{\mathrm{b}}$ & 10,697 & 0,000 \\
Kayın (\%) & $64,55 \pm 7,60^{\mathrm{a}}$ & $5,59 \pm 1,44^{\mathrm{b}}$ & $21,45 \pm 6,71^{\mathrm{b}}$ & $8,43 \pm 5,15^{\mathrm{b}}$ & 22,58 & 0,000 \\
Meşe-Kayın (\%) & $70,68 \pm 5,77^{\mathrm{a}}$ & $5,49 \pm 1,12^{\mathrm{b}}$ & $19,36 \pm 6,58^{\mathrm{b}}$ & $4,47 \pm 1,82^{\mathrm{b}}$ & 47,878 & 0,000
\end{tabular}

Aynı satırdaki aynı harfi taşıyan değerler istatistiksel olarak önemli değildir.

\subsection{Makrofaunanın Çeşitliliği}

Saf ve karışık meşcerelerde toprak makrofaunasının çeşitliliği yıl içerisinde dalgalanma göstermektedir. Ağustos, eylül, aralık ve mayıs aylarında makrofaunanın çeşitliliğinde meşcereler arasında istatistiksel fark $(P<0,05)$ bulunmuştur. Meşe-kayın meşceresi saf meşcerelere kıyasla daha yüksek çeşitliliğe sahipken mayıs 
ayında saf meşe meşceresinde çeşitlilik değeri diğer meşcerelere kıyasla istatistiksel olarak $(P<0,05)$ yüksek çıkmıştır (Şekil 5).

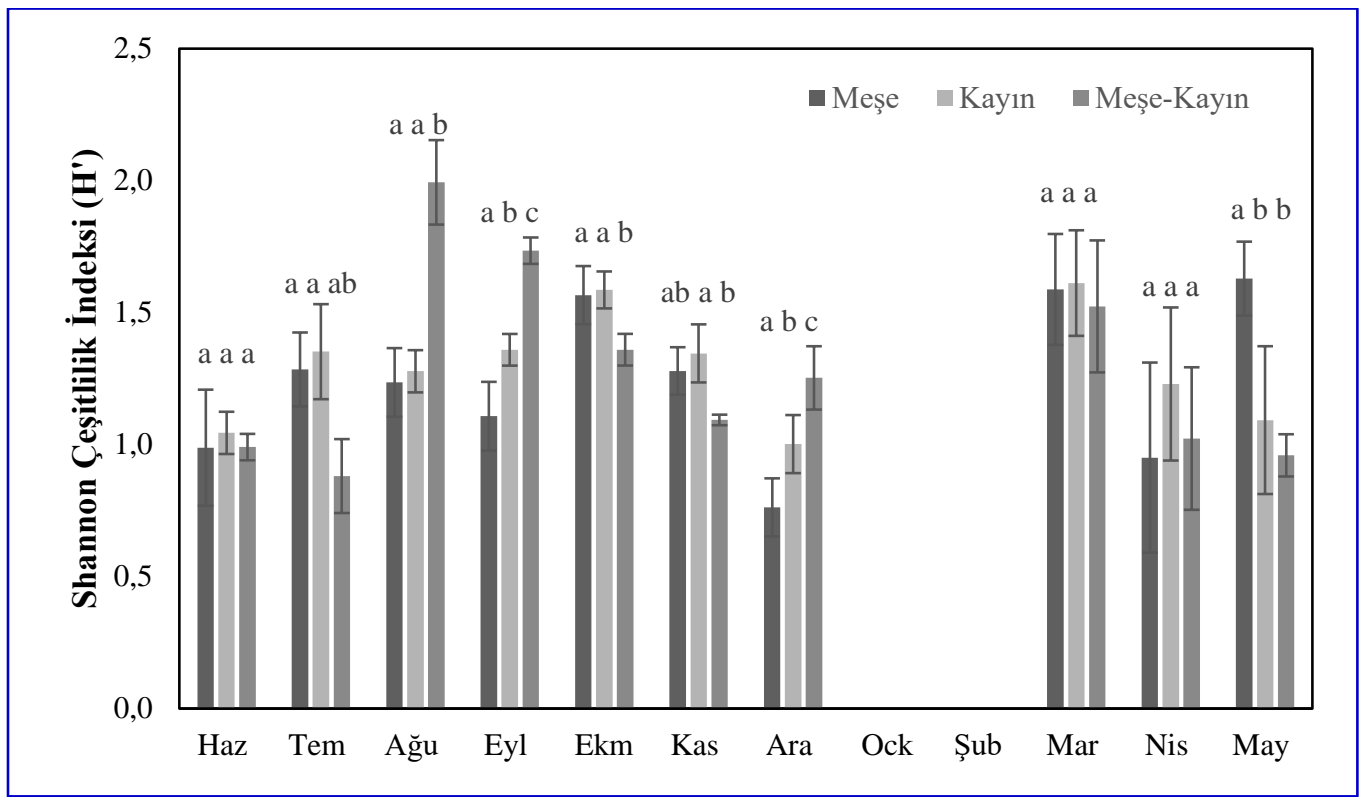

Şekil 5. Makrofaunaya ait aylık Shannon çeşitlilik indeksinin (ortıstd.hata) saf ve karışık meşcerelerdeki zamansal değişimi.

Meşe $\left(H^{\prime}=1,24\right)$, kayın $\left(H^{\prime}=1,29\right)$ ve meşe-kayın $\left(H^{\prime}=1,28\right)$ meşcerelerinde yıllık ortalama makrofauna çeşitliliği tekrarlı ölçümlerde varyans analizi yapıldığında istatistiksel fark göstermemiştir $(P=0,351)$. Fakat makrofauna çeşitliliğinin yıl içerisinde zamansal farklılık gösterdiği ve ayrıca her bir meşcerede de zamansal farklılık $(\mathrm{P}<0,05)$ olduğu belirlenmiştir (Tablo 3).

Tablo 4 Saf ve karışık meşcerelerdeki makrofauna çeşitliliğinin tekrarlı ölçümlerde ANOVA analiz sonuçları.

\begin{tabular}{lll}
\hline Shannon Çeşitlilik $\left(\boldsymbol{H}^{\prime}\right)$ & F & $\boldsymbol{P}$ \\
\hline Meşcere & 1,124 & 0,351 \\
Zaman & 9,540 & 0,000 \\
Meşcere x Zaman & 4,515 & 0,001 \\
\hline
\end{tabular}

\section{Tartışma ve Sonuç}

Makroeklembacaklıların miktarları karışık meşcerelerde, saf meşcerelere kıyasla daha fazladır (Aubert ve ark., 2003). Bu çalışmada meşe, kayın ve meşe-kayın meşcerelerinde yıllık ortalama makrofauna miktarı sırası ile 478 bry. $\mathrm{m}^{-2}, 470$ bry. $\mathrm{m}^{-2}$ ve 606 bry. $\mathrm{m}^{-2}$ olarak bulunmuştur. Belgrad ormanında yapılan bir çalışmada benzer olarak makrofauna miktarı meşe (Quercus petraea L.) meşceresinde 427 bry. $\mathrm{m}^{-2}$ ve çam (Pinus nigra Arnold) meşcerelerinde 921 bry. $\mathrm{m}^{-2}$ olarak belirlenmiştir (Cakir ve Makineci, 2013). Vehviläinen ve ark. (2008) karış1k meşcerelerin, saf meşcerelere kıyasla daha çok predatör tür içerdiğini, ağaç tür çeşitliliğinin özellikle örümcek (Areneae) miktarı üzerinde etkili olduğunu belirtmiştir. Benzer olarak, yapılan çalışmada meşe-kayın karışık alanındaki Areneae, Lithobiomorpha, Scolopendromorpha ve Carabidae gibi aktif avcıların miktarları saf alanlara kıyasla daha fazla bulunmuştur. Paquin ve Coderre (1997) yapmış oldukları çalışmada makrofauna miktarının ve çeşitliliğinin karışık ormanlarda daha yüksek olduğunu belirtmişlerdir.

Makrofaunanın büyük kısmı hızlı hareket eden canlılardır. Bu yüzden makrofaunanın alanlardaki miktar ve çeşitlilikleri hızlı değişebilmektedir. Yapılan çalışmada makrofauna çeşitliliği meşe $\left(H^{\prime}=1,24\right)$, kayın $\left(H^{\prime}=1,29\right)$ ve meşe-kayın $\left(H^{\prime}=1,28\right)$ meşceresinde göreceli olarak yüksek bulunmuştur. Palacios-Vargas ve ark. (2007) Quercus spp. ormanında yaptıkları çalışmada biyoçeşitliliğin meşcere yaşına bağlı olarak değişim gösterdiğini ve 15 yaşındaki alanda çeşitliliği $H^{\prime}=1,7$ bulurken 75 yaşındaki alanda $H^{\prime}=2,0$ bulmuştur. Santos ve ark. (2007) Portekiz'de zeytin alanlarında farklı tipteki çukur tuzakları kullanarak makroeklembacaklı çeşitliliğini $H^{\prime}=0,52-$ 
0,62 arasında bulmuştur. Aubert ve ark. (2003) makroeklembacaklı çeşitliliğinin karışık ormanda, saf ormana kıyasla daha yüksek olduğunu belirtmiştir. Loranger-Merciris ve ark. (2007) tropikal orman ile 50 yaşındaki plantasyondaki makroeklembacaklı yoğunluğu arasında önemli fark olmamasına rağmen çeşitliliğin plantasyonda daha yüksek olduğunu belirtmiştir. Bunun sebebi olarak da toprağın fiziksel ve kimyasal özelliklerinden kaynaklanabilecek farklar gösterilmektedir. Sonuç olarak, makroeklembacaklıların çeşitliliğini ağaç türü, karışımı ve yaşı ile birlikte yetişme ortamının etkilediği görülmektedir. Yapılan çalışmada makrofauna miktarı karışık meşcerede fazla bulunmasına rağmen çeşitlilik değeri bakımından farklılık belirlenememiştir.

Genel olarak, mevcut çalışmadan elde edilen sonuçlar ve literatür incelendiğinde, toprak makrofaunasının farklı ekosistemlerdeki komünite yapısının araştırılması elde edilen verilerin daha sağlıklı karşılaştırılması için gereklidir. Birçok çalışma makrofaunanın toprak sağlığının göstergesi olarak kullanıldığını göstermektedir (Rousseau ve ark., 2013; Kitamura ve ark., 2020). Makrofaunanın ekosistem süreçlerindeki yerleri ve çeşitliliklerinde meydana gelen değişimin ekosistem süreçlerine olan etkilerinin belirlenmesi ormancılık faaliyetlerine yön verici nitelikte olabilir.

\section{Teşekkür}

Bu makale, Meriç Çakır'ın doktora tezi sonuçlarını içermektedir. Ender Makineci yönetimindeki doktora tezi 2013 yılında İstanbul Üniversitesi Fen Bilimleri Enstitüsü'nde tamamlanmıştır. Bu çalışma, İstanbul Üniversitesi Bilimsel Araştırma Projeleri Koordinasyon Birimi, Proje numarası: 3122 tarafından desteklenmiştir.

\section{Kaynaklar}

1. Akburak, S., Makineci, E. (2016). Thinning effects on soil and microbial respiration in a coppiceoriginated Carpinus betulus L. stand in Turkey. For Biogeosc For, 9; 783.

2. Aubert, M., Hedde, M., Decaëns, T., Bureau, F., Margerie, P., Alard, D. (2003). Effects of tree canopy composition on earthworms and other macro-invertebrates in beech forests of Upper Normandy (France): The 7th international symposium on earthworm ecology· Cardiff · Wales· 2002. Pedobiologia, 47; 904912.

3. Barbier, S., Gosselin, F., Balandier, P. (2008). Influence of tree species on understory vegetation diversity and mechanisms involved - a critical review for temperate and boreal forests. Forest ecology and management, 254; 1-15.

4. Bardgett, R.D., van der Putten, W.H. (2014). Belowground biodiversity and ecosystem functioning. Nature, 515; 505-511.

5. Barros, E., Curmi, P., Hallaire, V., Chauvel, A., Lavelle, P. (2001). The role of macrofauna in the transformation and reversibility of soil structure of an oxisol in the process of forest to pasture conversion. Geoderma, 100; 193-213.

6. Binkley, D., Menyailo, O. (2005). Tree species effects on soils: implications for global change. Springer: Netherlands.

7. Cakir, M., Makineci, E. (2013). Humus characteristics and seasonal changes of soil arthropod communities in a natural sessile oak (Quercus petraea L.) stand and adjacent Austrian pine (Pinus nigra Arnold) plantation. Environmental Monitoring and Assessment, 185; 8943-8955.

8. Cavard, X., Macdonald, S.E., Bergeron, Y., Chen, H.Y. (2011). Importance of mixedwoods for biodiversity conservation: Evidence for understory plants, songbirds, soil fauna, and ectomycorrhizae in northern forests. Environmental Reviews, 19; 142-161.

9. Coleman, D.C., Crossley, D.A., Hendrix, P.F. (2004). Fundamentals of soil ecology. Academic Press: USA.

10. Çakır, M., Makineci, E. (2020). Litter decomposition in pure and mixed Quercus and Fagus stands as influenced by arthropods. The Journal of Forestry Research, 31; 1123-1137.

11. Çepel, N., Günay, T. (1984). Atatürk Arboretumu Toprak Raporu. Orman Toprak Tahlil Laboratuvarı, Eskişsehir.

12. Dindal, D.L. (1990). Soil biology guide. Wiley: New York.

13. Frouz, J., Elhottová, D., Kuráž, V., Šourková, M. (2006). Effects of soil macrofauna on other soil biota and soil formation in reclaimed and unreclaimed post mining sites: results of a field microcosm experiment. Applied Soil Ecology, 33; 308-320.

14. Hättenschwiler, S., Gasser, P. (2005). Soil animals alter plant litter diversity effects on decomposition. Proceedings of the National Academy of Sciences of the United States of America, 102; 1519-1524.

15. Jactel, H., Brockerhoff, E.G. (2007). Tree diversity reduces herbivory by forest insects. Ecology letters, 10 ; 835-848. 
16. Jones, C.G., Lawton, J.H., Shachak, M. (1994). Organisms as ecosystem engineers. Oikos; 373-386.

17. Karaöz, M.Ö. (1991). Atatürk arboretumu'ndaki bazı iğne yapraklı plantasyonlarda ölü örtünün kimyasal özellikleri üzerine araştırmalar. Journal of the Faculty of Forestry Istanbul University, 41; 68-86.

18. Kitamura, A.E., Tavares, R.L.M., Alves, M.C., Souza, Z.M.d., Siqueira, D.S. (2020). Soil macrofauna as bioindicator of the recovery of degraded Cerrado soil. Ciência Rural, 50.

19. Korboulewsky, N., Perez, G., Chauvat, M. (2016). How tree diversity affects soil fauna diversity: a review. Soil Biology and Biochemistry, 94; 94-106.

20. Leather, S. (2005). Insect sampling in forest ecosystems. Wiley-Blackwell: Oxfort, UK.

21. Lee, K., Foster, R. (1991). Soil fauna and soil structure. Soil Research, 29; 745-775.

22. Loranger-Merciris, G., Imbert, D., Bernhard-Reversat, F., Ponge, J.F., Lavelle, P. (2007). Soil fauna abundance and diversity in a secondary semi-evergreen forest in Guadeloupe (Lesser Antilles): influence of soil type and dominant tree species. Biology and Fertility of Soils, 44; 269-276.

23. Merlin, M., Perot, T., Perret, S., Korboulewsky, N., Vallet, P. (2015). Effects of stand composition and tree size on resistance and resilience to drought in sessile oak and Scots pine. Forest Ecology and Management, 339; 22-33.

24. MGM (2013). Orman ve Su İşleri Bakanlığı, Meteoroloji Genel Müdürlüğü, İstanbul-Kireçburnu istasyonu iklim verileri (2000-2013). In: İstanbul.

25. Özturna, A.G. (2013). Atatürk arboretumu (istanbul) topraklarının toprak kaynakları için dünya referans temeli’ne göre sınıflandırılması. Fenbilimleri Enstitüsü (Yüksek Lisans), İstanbul Üniversitesi, İstanbul.

26. Palacios-Vargas, J., Castano-Meneses, G., Gómez-Anaya, J., Martínez-Yrizar, A., Mejía-Recamier, B., Martínez-Sánchez, J. (2007). Litter and soil arthropods diversity and density in a tropical dry forest ecosystem in Western Mexico. Biodiversity and Conservation, 16; 3703-3717.

27. Paquin, P., Coderre, D. (1997). Changes in soil macroarthropod communities in relation to forest maturation through three successional stages in the Canadian boreal forest. Oecologia, 112; 104-111.

28. Petersen, H., Luxton, M. (1982). A comparative analysis of soil fauna populations and their role in decomposition processes. Oikos, 39; 288-388.

29. Pretzsch, H., Block, J., Dieler, J., Dong, P.H., Kohnle, U., Nagel, J., Spellmann, H., Zingg, A. (2010). Comparison between the productivity of pure and mixed stands of Norway spruce and European beech along an ecological gradient. Annals of Forest Science, 67; 712-724.

30. Rousseau, L., Fonte, S.J., Téllez, O., Van der Hoek, R., Lavelle, P. (2013). Soil macrofauna as indicators of soil quality and land use impacts in smallholder agroecosystems of western Nicaragua. Ecological indicators, 27; 71-82.

31. Salamon, J.A., Scheu, S., Schaefer, M. (2008). The Collembola community of pure and mixed stands of beech (Fagus sylvatica) and spruce (Picea abies) of different age. Pedobiologia, 51; 385-396.

32. Santos, S.A.P., Cabanas, J.E., Pereira, J.A. (2007). Abundance and diversity of soil arthropods in olive grove ecosystem (Portugal): Effect of pitfall trap type. European Journal of Soil Biology, 43; 77-83.

33. Scherer-Lorenzen, M., Schulze, E.-D. (2005). Forest diversity and function: temperate and boreal systems. Springer Science \& Business Media: Germany.

34. Scheu, S. (2005). Linkages between tree diversity, soil fauna and ecosystem processes. In, Forest Diversity and Function. Springer pp. 211-233.

35. Scheu, S., Albers, D., Alphei, J., Buryn, R., Klages, U., Migge, S., Platner, C., Salamon, J.A. (2003). The soil fauna community in pure and mixed stands of beech and spruce of different age: trophic structure and structuring forces. Oikos, 101; 225-238.

36. Shannon, C., Weaver, W. (1949). The Mathematical Theory of Communication. University of Illinois Pres: Urbana.

37. SPSS (2011). IBM SPSS statistics base 20. SPSS Incorporated, Chicago, IL.

38. Swift, M.J., Heal, W., Anderson, J.M. (1979). Decomposition in Terrestrial Ecosystems. University of California Press: Berkeley.

39. Vallet, P., Pérot, T. (2011). Silver fir stand productivity is enhanced when mixed with Norway spruce: evidence based on large-scale inventory data and a generic modelling approach. Journal of Vegetation Science, 22; 932-942.

40. Vehviläinen, H., Koricheva, J., Ruohomäki, K. (2008). Effects of stand tree species composition and diversity on abundance of predatory arthropods. Oikos, 117; 935-943.

41. Wardle, D.A., Bardgett, R.D., Klironomos, J.N., Setälä, H., Van Der Putten, W.H., Wall, D.H. (2004). Ecological linkages between aboveground and belowground biota. Science, 304; 1629-1633.

42. Wardle, D.A., Yeates, G.W., Barker, G.M., Bonner, K.I. (2006). The influence of plant litter diversity on decomposer abundance and diversity. Soil Biology and Biochemistry, 38; 1052-1062.

43. WRB (2006). IUSS Working Group, World reference base for soil resources 2006. 2nd edition. World Soil Resources Reports No. 103. FAO: Rome. 